\title{
COMPLIANCE E CRIMES CULPOSOS: A CATEGORIA DO RISCO PROIBIDO COMO PONTO DE UM “ENCONTRO MARCADO”
}

\author{
Fábio André Guaragni ${ }^{1}$ \\ Fernando Martins Maria Sobrinho ${ }^{2}$
}

\begin{abstract}
Resumo
Analisar-se-á, no artigo, primeiramente a origem e relevância do instituto do compliance em território brasileiro e seu diálogo com a área do Direito Penal Econômico, apreciando se o procedimento configura-se suficiente para manter a atividade empresarial em um patamar de risco permitido. A não observância de regras internas de compliance serve como referência para fundamentar, em situações concretas, a criação do chamado risco proibido? Antecedendo a resposta em método dedutivo, expor-se-á a respeito da teoria da imputação objetiva do resultado de lesão ao bem jurídico, fundada na previsibilidade de ultrapassagem da permissão de risco em empresas nas quais as regras de um manual de compliance são balizas para fixação de padrões de comportamento.
\end{abstract}

Palavras-Chave: Compliance; Risco Proibido; Crime Culposo; Previsibilidade; Direito Penal Econômico.

\section{INTRODUÇÃO}

Inserida em um cenário de expansão do discurso do dever-ser jurídico penal em direção ao controle de riscos da produção e distribuição de bens e serviços ao consumo, dá-se atualmente uma ascensão da compreensão pública dos crimes econômicos. Noutras palavras, assistimos ao aumento da percepção desta faixa de criminalidade, o que soa novidadeiro. É que, a partir da criminologia, tradicionalmente a criminalidade econômica é apontada como produtora de baixa sensibilidade no tecido social, nela situando-se delitos quanto aos quais há "ausência de afetividade" ou "crime appeal" (BAJO, 1982, p. 604). Opõe-se à criminalidade tradicional, contra bens jurídicos de corte individual, sobretudo em casos envolventes de violência ou grave ameaça.

\footnotetext{
${ }^{1}$ Doutorado em Direito das Relações Sociais, com ênfase em Direito Penal, pela Universidade Federal do Paraná (2002). Realizou estágio Pós-Doutoral na Università degli Studi di Milano (2012). Professor titular do Centro Universitário Curitiba UNICURITIBA, professor da Escola da Magistratura do Paraná - EMAP e professor da Fundação Escola do Ministério Público do Paraná - FEMPAR. E-mail: guaragni@mppr.mp.br

${ }^{2}$ Mestrando em Direito Empresarial e Cidadania pelo Centro Universitário Curitiba - UNICURITIBA. Membro do Conselho Editorial de periódicos especializados nacionais. Coordenador do periódico nacional (Informativo Virtual CAI) da Ordem dos Advogados do Brasil. Membro da Associação Paranaense dos Advogados Criminalistas (APACRIMI). Membro do grupo de pesquisa Direito Penal Econômico: repercussões da sociologia contemporânea coordenado pelo Professor Doutor Fábio André Guaragni. E-mail: fernandomariasobrinho@gmail.com
} 
Faz parte deste novo quadro de compreensão quanto aos crimes econômicos, que desponta inclusive pela midiatização frequente dos respectivos delitos, repercutindo sua alta lesividade, a percepção negativa dos entes coletivos empresariais. Afinal, é nos domínios das pessoas jurídicas que se dão as práticas ilícitas econômicas. Todo este horizonte deu centralidade, nos debates acadêmicos em curso no Brasil, à relação entre a matéria criminal e sua contemplação em manuais de compliance.

Com esta consideração inicial, pretende-se aqui desenvolver o estudo do instituto do compliance inserido na mirada do Direito Penal Econômico. O instituto somente teve seu conhecimento trasladado para o âmbito disciplinar jurídico-penal, disseminando-se como objeto do olhar de juristas em todo o país, com a promulgação das reformas de julho de 2012 na Lei de Lavagem de Dinheiro (Lei 12.683/12, que alterou a redação original da Lei 9.613/98) e com a mais recente edição da Lei Anticorrupção 12.846/2013, em cujo bojo a adoção de programas de cumprimento de normas serve como causa de atenuação das penalidades previstas para a pessoa jurídica pela prática de atos de corrupção lato sensu.

Os temas primordiais deste texto dizem com o impacto dos programas de cumprimento de normas para medir o patamar de riscos proibidos para a atividade empresarial e suas instituições. No âmbito da imputação objetiva de resultados de lesão a sujeitos ativos de delito, a criminalização exige a constatação do elemento típico da quebra de um cuidado objetivo devido ou a superação de um patamar de risco tolerado. Dá-se divergência entre a conduta realizada e aquela conduta adequada, segundo um padrão comportamental limitado por contornos de risco permitido. Especula-se, aqui, se esta divergência pode ser apurada a partir da não observação do próprio programa interno de cumprimento de normas de uma unidade empresarial.

Assim, tomando a revisão bibliográfica como método de pesquisa, o texto desenvolve considerações relativas ao universo corporativo-empresarial como cenário de crimes culposos e de regras de compliance, que se entrecruzam no ponto comum da observância ou não de cuidados objetivos. O questionamento de partida, a ser objeto de exploração, pode ser assim redigido: a não observância de regras internas de compliance serve como referência para fundamentar, em situações concretas, a criação do chamado risco proibido?

\section{O INSTITUTO DO COMPLIANCE E O DIREITO PENAL ECONÔMICO}

O compliance, para os Norte-Americanos, é compreendido como um sistema de organização empresarial e está intimamente ligado a chamada "corporate governance" (AGLIETTA; REBÉRIOUX, 2005, p. 174). Analisando-se semanticamente, a palavra compliance tem sua origem do verbo to comply, traduzido para o português como "cumprir" ou como "um agir conforme uma regra" ou ainda "agir conforme uma ordem" (WEBER, 2001, p. 67). 
É dizer, compliance é um procedimento adotado pelas empresas - em seu âmbito interno - para o cumprimento de mecanismos de controle que venham a prevenir riscos ou o cometimento de irregularidades dentro do âmbito empresarial, bem como identificá-las quando praticadas. Para operar, um programa de compliance vale-se, como regra, de códigos internos, formulados e adotados pelas pessoas jurídicas. Referidos códigos dão suporte ao cumprimento do ordenamento jurídico externo à organização e balizam os patamares de riscos aceitáveis para realização das atividades inerentes ao ramo.

Quando em andamento, o programa de compliance preocupa-se com o grau de adesão dos destinatários da norma nos respectivos processos de atuação, forjando uma cultura interna de cumprimento normativo, condição necessária para a governança efetiva, baseado na transparência (DEACON, 2007, p. 38). Objetiva não só prevenir ilícitos penais (criminal compliance) e extrapenais, mas também visa coibir ilícitos éticos dentro da empresa (SANCHEZ, 2013, p. 93).

Somente nos últimos anos esse instituto começou a tomar forma no Brasil, conquanto a origem dos programas de compliance situe-se há cerca de cem anos, no âmbito de instituições financeiras e empresas, com a criação do Banco Central Americano (1913), cujo objetivo foi o de construir um sistema financeiro mais seguro e estável (MANZI, 2008, p. 123). No Brasil, a relevância dos programas de compliance no mundo jurídico-penal ganhou força com a edição da Lei 9.613/98 (Lei de Lavagem de Dinheiro). Porém, somente com as alterações desta, após a edição da Lei 12.683/12, e com a publicação da Lei 12.846/13 (Lei Anticorrupção) - que contém expressão de um direito sancionador judicial, com matizes de direito penal, conquanto não carregue o rol de garantias típico deste universo -, o tema passou definitivamente ao horizonte de estudo do direito penal econômico.

De fato, o compliance traça um diálogo direto com o Direito Penal Econômico, cujo teor permanece em boa medida inexplorado na pesquisa científica criminal. As repercussões jurídicas do tema concentram-se no direito econômico empresarial, já que - antes de uma direta preocupação com crimes - os programas de compliance trazem critério morais e extrapenais, voltados para uma nova cultura corporativa.

Porém, a partir de um discurso do dever-ser jurídico penal que se expandiu em direção à contenção de riscos no universo da produção e distribuição de bens e serviços ao consumo, deu-se um aumento da percepção pública aos crimes econômicos. Este aumento de percepção, aliado à repercussão negativa para a imagem do ente coletivo em cujo âmbito as práticas ilícitas ocorrem, deu à matéria criminal posição de centralidade nos programas de compliance. Deriva daí o criminal compliance, instrumento empresarial voltado à prevenção e identificação ex post factum de ilícitos penais no universo corporativo. Referido instrumento ganha destaque em empresas que irão se relacionar com o poder público, sobretudo através de contratos derivados de licitações. Porém, transcende este universo restrito. Pode ter por alvo prevenir crimes atinentes ao público interno, como assédio sexual, crimes 
contra a organização do trabalho, relacionados à anotação de documentação laboral, bem como ao público externo, ressaltando o interesse pela preservação de bens supraindividuais (v.g., dos consumidores de produtos e serviços da empresa), bem como o Estado (por exemplo, crimes fiscais e previdenciários). Neste contexto, para guiar a implantação de programas internos de cumprimento, ganha importância o "parecer jurídico externo", enquanto ato opinativo e consultivo de agentes externos ao ente coletivo (cujo teor pode levar à eventual responsabilidade penal e extrapenal do emitente).

Assim, ao invés de reagir somente ex post factum, face a condutas ilícitas comissivas ou omissivas que já violaram um bem jurídico penalmente relevante, o ente empresarial, através do criminal compliance, trata os mesmos fenômenos ex ante factum: partindo dos controles internos e das medidas que possam de alguma maneira prevenir a prática criminosa, antecipa o comportamento penalmente relevante. Vale-se fundamentalmente da assessoria jurídica (SAAVEDRA, 2011, p. 11-12).

Neste sentido, o criminal compliance implica em privatização da mecânica preventiva do direito penal, tradicionalmente operada através do Estado. Lado outro, evidencia que o Estado passou a dividir o papel de gestor de riscos com outros agentes, num claro fenômeno de democratização da gestão dos riscos.

Tudo deriva da emergência da categoria "risco" como protagonista das tomadas de decisões políticas, caracterizando a "sociedade de risco" indicada por ULRICH BECK:

A representação do risco mundial leva a produzir, a construir socialmente a realidade, de maneira que o risco é causa e meio da reconfiguração social e está estreitamente relacionado (...) com as novas formas de classificar, interpretar e organizar nossa cotidianidade e de representar, organizar, viver e configurar a sociedade a afim de fazer presente o futuro. (BECK, 2006, p. 37)

$\mathrm{Na}$ sociedade de risco, todas as decisões políticas movem-se em torno do aumento da percepção do risco, enquanto "antecipação da catástrofe" (BECK, 2008, p. 27) proveniente de decisões humanas (LUHMANN, 2006, p. 67). E, de fato, este é o panorama mais comum das decisões políticas vivenciado nas últimas décadas. As catástrofes antecipadas - por exemplo, ambientais, derivadas do comércio de substâncias medicinais mal testadas - são capazes de atingir todos, sendo um problema de todos. O risco, neste sentido, é uma categoria democrática (GUARAGNI, 2009, pp. 55-65).

Esta centralidade dos riscos como mote das decisões políticas (incluindo-se aí a política criminal), aliada ao fracasso estatal na contenção de tragédias derivadas do emprego de tecnologias de risco - e ao próprio declínio da agência Estado como sede do poder - faz com que, através da legislação, sejam convocados para a tarefa de contenção de patamares de risco todos os demais agentes sociais. Sintético, BECK enuncia que "os três pilares da segurança estão desgastados - o Estado, a ciência e a economia fracassam na provisão de segurança - e nomeiam ao "cidadão consciente de si" seu herdeiro legal" (BECK, 2008, p. 63). 
Naturalmente, avultam os geradores dos riscos dentre estes agentes que passam a ser, ao lado do Estado, encarregados de gerirem os riscos procedentes de suas atividades. Assim, "é só o vértice [da atividade empresária] que possui uma possibilidade de conhecimento da estrutura empresarial, da organização de homens e meios: a sua contribuição é fundamental e não eliminável” (ALESSANDRI, 2010, p. 77) como parte de um programa de descentralização e democratização da gestão dos riscos.

Diante de tudo isso, num fenômeno típico do atual perfil de sociedade, a adoção de programas de criminal compliance simboliza democratização e privatização da gestão de riscos. Democratização à medida em que os submetidos aos riscos passam a operar, também, como controladores; privatização, porque desloca para o universo privado uma atividade a princípio vista como exclusivamente estatal. Esse dever de estar em conformidade e fazer cumprir os regulamentos internos e externos impostos às atividades empresariais exige o desenvolvimento de códigos de ética nas organizações, bem como seleção e treinamento de profissionais com capacidade de identificar situações potenciais de crimes enquanto alvos centrais da pretensão maior de evitar, mediante canais próprios, condutas antiéticas, geradoras de dilemas de atuação (MANZI, 2008, p. 166).

Feitas estas considerações iniciais, explora-se na sequência a categoria dogmática dos crimes culposos, para posteriormente cruzá-la com o tema do compliance. De antemão, anuncia-se que há um "encontro marcado" entre ambas no específico ponto da definição dos patamares de risco proibido e das circunstâncias de delineamento da previsibilidade objetiva do evento por parte do sujeito ativo.

\section{TIPOS CULPOSOS: BASES DISTINTIVAS DO RESPECTIVO COTEJO COM OS TIPOS DOLOSOS}

Dentro de um crescente normativização do direito penal, é costume afirmar que os crimes dolosos são culposos com o acréscimo do dolo, enquanto expressão de vontade comunicada no comportamento realizado (i.é, um dolo não concebido como dado psíquico, mas atribuído a alguém a partir do quadro comunicativo estabelecido pela conduta) (JAKOBS, 1997, p. 325). Excepcionalmente, o legislador penal considera o desvalor de ação encerrado somente na quebra do cuidado devido como bastante para a censura típica, dispensando o acréscimo derivado do dolo, enquanto expressão de tipicidade subjetiva. Por força disso, os crimes dolosos são regra e, os culposos, exceção. Cada tipo culposo se encontra correspondido por um tipo doloso, com pena amenizada em relação a este. A cominação punitiva inferior ou menos grave tem seu fundamento na valoração dessas ações como ilícitos de menor transcendência, o que acaba por demonstrar não existirem delitos culposos (MAURACH, 1995, p. 528).

O dolo é o conhecimento e vontade de realizar os elementos objetivos do tipo. Em contrapartida, atua de forma culposa (ou imprudente, segundo a terminologia espanhola, pela qual delitos "imprudentes" equivalem à 
expressão portuguesa delitos "culposos") quem, sem o elemento cognitivo, realiza o tipo objetivo em consequência de uma infração ao cuidado objetivo devido, quando the era objetivamente previsível o evento. É possível, excepcionalmente, que o agente opere com cognição da situação de risco objetivo, crendo na não superveniência do resultado lesivo. Havendo fatores concretos que motivem referida crença - e não um puro otimismo ou fé na sorte -, dá-se a culpa consciente. A culpa não é, portanto, uma forma atenuada de dolo, mas algo diverso deste. O conteúdo de injusto e de culpabilidade do delito imprudente é inferior ao de um delito doloso similar, pois aqui o autor não contraria a lei voluntariamente, mas atua de forma distraída (JESCHECK; WEIGEND, 2003, p. 606).

Nos crimes dolosos a vontade está direcionada à realização integral do tipo, ao contrário dos delitos culposos. No entanto, pressupõe-se que, quando realizado um tipo culposo, ele se realizou de forma integral uma vez que não existe tentativa culposa. Isso significa dizer que sempre que um indivíduo é responsabilizado por um crime culposo, ocorre a "responsabilização pelo acaso" (DIAS, 2004, P. 637). Culpa é, portanto, a não observância do cuidado objetivo devido, manifestada em uma conduta que produzirá um resultado não querido, mas que podia ser previsto (BITENCOURT, 200, p. 320).

No período causal-naturalista, caracterizou-se a imprudência como uma forma de culpabilidade, no marco da chamada teoria psicológica da culpabilidade. A culpabilidade, a seu turno, era uma relação psíquica do autor com sua ação danosa. Esta perspectiva, vinculada estreitamente com o axioma "toda culpabilidade é culpabilidade de vontade", levada ao pé-da-letra, só possibilitava sancionar como imprudência a chamada culpa consciente. Afinal, a culpa inconsciente caracteriza-se justamente pela falta da relação psíquica, eis que o agente não prevê o evento, ainda que lhe seja possível. É curial que a possibilidade de um nexo psíquico não é um nexo psíquico. Nela, era impossível demonstrar a existência de uma relação psicológica entre o sujeito e o resultado, eis que não o representou (BACIGALUPO, 1999, p. 340).

A possibilidade de conhecimento do resultado ou do perigo é também uma característica do atuar imprudente. Já a representação efetiva do resultado não transformará o comportamento em prudente, mas em consciente (OLIVARES, 1992, p. 353).

O tipo culposo tem como característica essencial sua peculiar forma de individualização da ação proibida. O tipo culposo permanece, prima facie, indefinido, e só é possível particularizá-lo em cada caso após a determinação da conduta que origina o resultado penalmente relevante. $\mathrm{O}$ tipo penal culposo não castiga o autor pela forma com que o fim é perseguido, mas porque ao final pressupõe que o agente deu causa a um perigo proibido, previsível e evitável. 
A mera criação de um perigo, porém, não é suficiente para a imputação culposa. Isso não significa que a ação não tem uma finalidade, mas que esta - em regra - não está proibida em razão dessa finalidade 3 . É necessário, portanto, analisar a finalidade em cada caso concreto para saber de qual ação querida se tratava e, com isso, determinar qual a ação pretendida. Só então é possivel determinar qual era o cuidado correspondente indispensável para fechar o tipo e verificar a tipicidade (ZAFARONI, 202, P. 549). Assim, tanto nos crimes culposos como nos dolosos, a conduta é orientada pela finalidade. Porém, no culposo a finalidade serve apenas para indicar qual era o cuidado devido na situação concreta - segundo o fim buscado - e, portanto, o grau de reprovabilidade da conduta. O tipo culposo exige um conhecimento potencial do resultado lesivo possível, não sendo, então, necessário, um conhecimento efetivo para se caracterizar (no que também se distingue do dolo). Tal conhecimento potencial deve ser provado de forma exaustiva, não bastando indícios ou presunções (PIERANGELI, 2007, p. 50).

É necessária, então, para a caracterização do delito culposo, a falta da vontade acerca do fato, que caracteriza o dolo. No delito culposo o agente realizou o fato previsto na lei como resultado de uma conduta querida por ele, mas que não havia aceitado direta ou indiretamente. Então, para a ocorrência de um delito culposo é necessário que o resultado decorra de uma conduta imprudente, negligente ou imperita, ou de uma inobservância de um dever de cuidado, disciplinado na norma (ANTOLISEI, 2000, p. 365-366).

\section{RESPONSABILIDADE PENAL CULPOSA E TEORIA DA IMPUTAÇÃO OBJETIVA}

Uma das questões mais complexas do hodierno direito penal empresarial diz respeito à caracterização da responsabilidade penal culposa por parte dos empresários. Partindo da premissa de que o Direito Penal Econômico não é um ramo do direito econômico, mas sim do direito penal, que se ocupa de setores específicos da vida social, as categorias dogmáticas criadas em geral para o direito penal tradicional mantêm-se aplicáveis no âmbito dos delitos socioeconômicos (SANCHEZ, 2010, p. 66). Porém, sofrem alguns ajustes e adaptações.

Veja-se a teoria da imputação objetiva. Usualmente, opera agregando critérios axiológicos para a imputação, ao agente, do resultado jurídico no tipo objetivo. Com isto, supera a configuração da tipicidade objetiva pela mera imputação ao agente de um resultado naturalístico, mediante nexo de causalidade. Porém, nos crimes econômicos, a normativização da tipicidade apresenta vantagens de política-criminal adicionais: assim, a teoria da imputação objetiva permite que haja uma redução da intervenção estatal mediante o reforço de um injusto penal, cujo cerne evidencie a geração material de risco para o bem de proteção penal, com um consequente afastamento de critérios exclusivamente formais para a tipificação objetiva. Facilita a pretensão do

\footnotetext{
${ }^{3}$ É costumeira a afirmação de que no crime culposo a finalidade não é proibida. Ora, é possível que alguém, durante a prática de um crime doloso, quebre cuidados devidos na execução da correlata conduta e gere resultados puníveis culposamente. Então, para além da punição pelo crime doloso, haverá crime culposo em situação na qual o fim do agente era proibido.
} vol.09, n. 01, Rio de Janeiro, 2016.pp. 272-287 
direito penal de resultar em uma pena justa e necessária, excluindo uma responsabilidade penal demasiadamente formal (SANCHEZ, 2010, p. 67). Alguém poderia considerar que esta vantagem opera em todos os crimes. Porém, no direito penal econômico, certa "administrativização" tem como consequências um nivelamento da norma penal à norma administrativa, bem como uma deriva do Estado no sentido de proteger a própria administração pública mediante normas penais. E - nestes movimentos - os tipos penais muitas vezes convertem-se em violações de regulamentos e atos concretos do administrador, como licenças. Neste passo, os tipos convolam-se em violações puras e simples de normas, formalizando-se. Os critérios axiológicos de imputação objetiva funcionam como antídoto para o problema derivado da aplicação de tipos penais meramente formais ao apelarem para o conteúdo material do injusto, reforçando-o enquanto lesão ou perigo de lesão para bens jurídicos.

Imperioso ressaltar que a imputação objetiva neste trabalho é entendida como uma teoria global sobre a imputação de injustos penais às pessoas. Somente a partir deste viés de compreensão da teoria da imputação objetiva é que se consegue atingir um juízo de valoração que realize adequadamente a verificação da correspondência objetiva entre a conduta realizada e o tipo de bens a que a norma penal se volta para evitar lesões. Para JAKOBS (1997, p. 353), se no âmbito da organização empresarial o administrador da empresa deixa de adotar práticas de segurança ou se produz, nos casos de ingerência, alguma prática que incremente o risco, dá-se a criação de um risco proibido.

Para enquadrar os critérios de imputação objetiva nos crimes culposos, convém recordar que, neles, fazse necessária a presença em regra de seis elementos: conduta, resultado naturalístico, nexo causal, quebra de cuidado objetivo devido, relação de determinabilidade entre quebra de cuidado e resultado, e previsibilidade objetiva do resultado associada à ausência de previsão pelo agente. Excepcionalmente, o tipo culposo é formal ou de mera atividade, abdicando de resultado naturalístico e nexo causal (por ex., art. 7º, IX e parágrafo único, Lei 8137/90). Os critérios de imputação operam no quadro elemento: servem para estabelecer se houve a quebra do cuidado objetivo devido. Operam também no quinto elemento: servem à definição da conexão entre quebra de cuidado devido e resultado (relação de determinabilidade).

Toda norma jurídica que declara puníveis comportamentos culposos (bem como dolosos) exige de qualquer pessoa o emprego de um devido cuidado objetivo, que resulta necessário para evitar a realização do tipo. Por regra geral, os tipos penais culposos não dão informação sobre a classe e a medida de cuidado aplicável (JESCHECK; WEIGEND, 2003, p. 622).

A referência a deveres de cuidado oriundos de pautas sociais não significa invocação do chamado "homem médio". O cuidado devido deve ser determinado a cada caso, levando-se em conta a situação social e 
jurídica de cada pessoa. São diferentes os cuidados exigidos de uma pessoa comum e um motorista profissional, tal como taxistas e motoristas de ônibus, por exemplo (ZAFARONI, 2006, p. 439-440).

O importante no tipo culposo não é o resultado em si, mas, sim, o modo como a ação que o causou se realiza. A observância do cuidado objetivo devido é, portanto, elemento fundamental desta modalidade de injusto. Quando há dúvida sobre a ação devida, existe para o agente o dever de abster-se de praticar a ação, pois quem se arrisca age com imprudência e, existindo um resultado típico, o agente torna-se autor de um crime culposo (BITENCOURT, 2000, p. 207).

A observância do cuidado devido adverte a presença de perigo em sua gravidade aproximada, como pressuposto de toda ação prudente. Resulta da advertência derivada deste cuidado devido a atribuição de uma punição à culpa inconsciente: esta supõe a imprudente falta de previsão de perigo. $O$ primeiro cuidado objetivo devido consiste em identificar e valorar corretamente os perigos que cercam o bem jurídico protegido, pois todas as precauções destinadas a evitar o dano dependem do conhecimento do perigo ameaçador. Trata-se, então, de um dever interno, um dever de exame preliminar de observar as condições sob as quais a ação tem lugar. Para o grau de atenção exigivel são especialmente importantes a proximidade do perigo e o valor do bem jurídico exposto a risco (JESCHECK; WEIGEND, 2003, p. 622).

Assim, a ofensa ao cuidado devido é resultado da ação contrária à imposta pela norma a fim de se atingir as funções protetivas esperadas. O tipo culposo só pode ser comprovado na forma negativa, isto é, se o agente agiu com o devido cuidado e mesmo assim existiu resultado, a conduta é atípica ao passo que, se na condução da atividade, não foram observados os deveres exigidos, haverá lesão ao bem jurídico punível (TAVARES, 2004, p. 138).

O cuidado objetivo tem também dimensão externa, consistente no agente comportar-se externamente conforme a norma de cuidado que pode, previamente, advertir. Possui três manifestações principais. A primeira é o cuidado de não praticar ações perigosas. Há ações que são tão perigosas que não podem ser praticadas sem infringir o dever de cuidado. Aqui se encaixam os casos de falta de preparação técnica. Cuidados de preparação e informação prévia também se constituem como parte da dimensão externa dos cuidados, antes de empreender certas situações que podem ser perigosas (ex:: o médico, antes de tomar decisões, deve examinar atentamente o paciente). Por fim, o cuidado de atuar prudentemente em situações perigosas: não é preciso se omitir das ações perigosas, mas deve-se realizá-las com a máxima atenção para evitar que o perigo se converta em lesão (PUIG, 2002, p. 296).

Não basta apenas que a existência da violação ao cuidado devido cause um determinado resultado. Além disso, deve existir uma relação determinante entre a violação do cuidado devido e o resultado, ou seja, para a ocorrência do resultado a violação do dever de cuidado deve ser determinante. Tal relação não é de causalidade, 
mas de determinabilidade. Verifica-se não se a conduta produziu o resultado, mas se o descuido nela embutido produziu o resultado. A pergunta que se faz é "haveria resultado sem o descuido" (ZAFARONI, 2006, p, 441)?

A infração do cuidado devido precisa ter como resultado a realização da parte objetiva de uma ação prevista em um tipo doloso. Tal resultado pode consistir tanto em um resultado naturalístico separado da conduta, como na parte objetiva de uma conduta descrita em um tipo doloso de mera atividade ou formal. Em ambos os casos é preciso que a ação resultante tenha sido causada pela infração ao cuidado objetivo devido e haja a citada relação de determinabilidade (PUIG, 2002, p. 300).

Assim, para caracterizar um delito culposo, não é necessária apenas a quebra no dever de cuidado, mas também que sobrevenha um resultado típico. Existe nos delitos culposos um "defeito de programação da causalidade com relação ao dever de cuidado exigivel" (ZAFARONI, 1988, p. 79), e necessita-se observar se o resultado era previsível.

Dá-se a previsibilidade quando o agente, nas circunstâncias do fato, podia, segundo seu conhecimento geral, representar a ocorrência do resultado. É na previsibilidade que se fundamenta de forma decisiva a culpa, ou seja, é dizer que a previsibilidade está intrínseca à essência da culpa. A previsibilidade nada mais é do que a possibilidade de antever mentalmente um evento na maioria das vezes ligado à evitabilidade do resultado. Essa previsão, portanto, condiciona o dever objetivo de cuidado: quem não pode prever não tem o dever de cuidado e então não pode violá-lo (PIERANGELI, 2007, p. 53). Trata-se do caso fortuito, ou imprevisibilidade objetiva.

Para a imputação do resultado não é suficiente que tenha existido um comportamento do autor, mas que o resultado só possa ser imputado ao autor quando aquele tenha precisamente como pressuposto específico o caráter descuidado do comportamento do agente, posto que o injusto de ação do autor imprudente reside apenas na infração do cuidado devido. A especial relação de antijuridicidade com o cuidado devido não é outra senão a aplicação da teoria da imputação objetiva aos delitos culposos. Dessa relação resultam duas coisas: a primeira é que o resultado teria sido evitado com um comportamento diligente, e a segunda é que a norma infringida pela ação descuidada está destinada, no caso concreto, precisamente à evitação de um resultado dessa natureza (JESCHECK; WEIGEND, 2003, p. 630).

Por fim, observe-se que o CP atribui culpa ao agente sob três formas: segundo o art. 18, II, ocorre por imprudência, negligência ou imperícia. São "batismos" das quebras de cuidado objetivo devido, nomes dados às situações em que o agente transcende os patamares de risco permitido.

Diz-se imprudente a conduta arriscada ou perigosa e que possui caráter comissivo. A característica da conduta imprudente é a intempestividade, precipitação, insensatez ou imoderação. Se o agente tivesse prestado mais atenção poderia ter previsto o resultado. Outro ponto essencial da imprudência é a simultaneidade entre a 
culpa e a ação. À medida em que o agente pratica a ação, a imprudência vai sendo desenvolvida concomitantemente (BITENCOURT, 2008, p. 286).

Negligência é a falta de cuidado do agente que, podendo, não adota as precauções necessárias. É um não fazer o que era obrigado a ser feito. Não é um fato psicológico, mas sim um juízo de apreciação. No caso dos crimes de negligência, o autor não imagina o resultado, ficando este fora de seus pensamentos. Ao contrário do que ocorre na imprudência, a negligência é anterior à ação, uma vez que significa o não praticar uma conduta que deveria ter sido feita antes de agir.

Imperícia é a quebra de regra técnica e pressupõe uma arte, ofício ou profissão. Consiste na incapacidade ou falta de conhecimento do agente para praticar determinada conduta. Trata-se de uma ação inidônea em uma tarefa que demanda uma especial destreza. É uma maior exigência formulada a quem se dedica à atividade que carrega grande risco e, por esse motivo, deve ser desenvolvida com especial habilidade.

\section{O "ENCONTRO MARCADO": REGRAS E PRÁTICAS DE COMPLIANCE COMO BASE PARA FIXAR O CUIDADO OBJETIVO DEVIDO E DELINEAR O CAMPO DE PREVISIBILIDADE OBJETIVA ENQUANTO ELEMENTOS DO CRIME CULPOSO}

Expostos os elementos do tipo culposo, é possível visualizar com clareza a maneira como neles se integra um programa de compliance. A constatação do elemento típico consistente na quebra de um cuidado objetivo devido dá-se através da fixação da conduta esperada como padrão comportamental para a situação concreta (standard de comportamento) e da posterior comparação deste padrão com a ação concreta do agente. Quando a ação concreta diverge do standard, evidenciando ultrapassagem do patamar de risco padronizado, o elemento típico culposo da quebra do cuidado devido fica caracterizado.

Se, dentro do universo corporativo, há um manual de compliance, suas regras serão balizas para fixação dos padrões de comportamento que implicam em risco permitido, desde que referidas regras - evidentemente não divirjam da normativa externa ao ente empresarial. De fato, regras de compliance atentas à normativa externa (normas penais, extrapenais de segurança e até não estatais, como regras corporativas) podem levá-la a minúcias, segundo as tipicidades do setor econômico da empresa, "customizando-as" pelas peculiaridades respectivas. A adaptação da normativa externa, através de normativa interna empresarial, cria standards de conduta específicos e diretamente relacionados aos riscos da concreta atividade. Com isso, a baliza para detectar a quebra do cuidado devido ganha inegável consistência.

Em contraponto, um manual de compliance desservirá como referência para os standards de comportamento cuidadoso se não estiver compassado com a normativa externa, penal e extrapenal (especialmente administrativa), destinada à proteção de bens jurídicos e contenção de patamares de riscos. 
Por outro lado, um programa de cumprimento normativo implica em treinamento dos núcleos organizacionais geradores dos riscos cujo rebaixamento se pretende. Nestes termos, também as práticas treinadas e as próprias rotinas de treinamento servirão para fixar os parâmetros de cuidado objetivo devido. Uma vez ultrapassados, darão suporte à detecção de um elemento típico dos crimes culposos - a quebra do cuidado devido -, sugerindo a eventual prática de crime culposo no âmbito da organização.

Ademais, há ainda outro impacto da adoção de programas de compliance na organização empresária em relação a crimes culposos porventura realizados em seu âmbito. Incide sobre o juízo acerca da existência, ou não, de previsibilidade objetiva do resultado danoso na situação concreta. É que a instauração de um programa de compliance sugere, para os setores da organização a ele submetidos, um alerta respectivo à contenção de riscos diretamente jungidos às suas atividades. Nestes termos, o compliance gera um sinal amarelo de advertência no universo das atividades de risco, concretizados em cada ação para a qual: 1- o manual prevê cautelas; 2- o programa instituiu específicos treinamentos para contenção de riscos. Assim, reforça os deveres de informação, cuja presença derivaria já da própria existência de uma dúvida sobre uma conduta delitiva ${ }^{4}$. De fato, quando para o sujeito surge uma dúvida, também surge o dever de resolvê-la. A decisão sobre o que é ilícito ou lícito vem da criação do legislador, através de ordenamentos jurídicos codificados e, então, a dúvida instaura uma proibição dilatória - informe-se -, e não uma proibição categórica - omita-se (LEITE, 2013, p. 144-145).

Este dever de informar-se para além da dúvida ganha uma segunda fonte na própria relação empregatícia, quando se impõe ao empregado o dever de informar-se como parte de sua atividade laboral, a partir de treinamento de compliance e da existência de um manual com rotinas de procedimentos de cuidado a serem observados. Também fica, para o empresário, a obrigação residual de verificar se o programa está funcionando, bem como do compliance officer, no mesmo sentido.

\section{CONCLUSÃO}

Com as considerações traçadas, conclui-se que todo este contexto circunstancia os elementos a partir dos quais se forma o juízo de que um dado resultado lesivo era, no âmbito da organização empresária, previsível por parte do agente, pressupondo-se outro com idênticas capacidades, segundo a multicitada teoria individualizadora. Por ela, apura-se a previsibilidade objetiva do resultado, pelo agente, a partir da projeção daquilo que diversas pessoas, com idênticas capacidades, teriam conseguido prever na situação concreta.

\footnotetext{
${ }^{4}$ Os critérios que orientam o dever de informação são: o cumprimento de um dever de informação, o grau de plausibilidade jurisdicional da dúvida, a necessidade de atuar nos limites desta dúvida. O cumprimento do dever de informação e atuar nos limites da dúvida sempre devem ser analisados de uma forma mais objetiva, na medida em que ou o sujeito cumpriu este dever ou não; ou se atuou nos limites, ou não. Já a plausibilidade jurisdicional da dúvida é um critério graduável e deve ser analisado de uma maneira mais elástica.
} 
Por outro lado, deve-se atentar para os deveres de cuidado cometidos ao próprio empresário. Concentram-se, sobretudo, no dever de vigilância dos riscos que sua atividade empreendedora gera, por força da realização de comportamentos não por sua direta iniciativa, mas pelas iniciativas dos delegados-empregados em divisão de tarefas. A criação de um programa de compliance reforça a ideia de que observa deveres de cuidado, mas não basta. Se o empresário não se exonerar do seu dever de informação através de constante e rotineiro acompanhamento do real funcionamento do programa, não é possível afirmar que observou os cuidados devidos. Também não o faz se, informado pelo compliance officer de concretos comportamentos criminosos detectados no âmbito empresarial, não reage (a imputação do crime ao empresário dependerá da previsão de forma culposa ou, no limite, poderá ocorrer até mesmo a título de dolo, nomeadamente pela modalidade do dolo eventual).

Mutatis mutandis, o programa interno de cumprimento exime o sujeito ativo de uma possível prática culposa quando, previamente à sua conduta, ele se vale do manual interno de cumprimento de normas ou de direta consulta ao compliance officer e, através das informações obtidas, necessárias para suprir o cuidado devido, dá continuidade à sua ação. Se o manual ou a orientação estiver divorciado da normativa externa, desde que não tenha o agente como alcançá-la e estando convicto de que está dentro do risco permitido balizado pelo programa de compliance, ser-lhe-á impossível chegar à previsibilidade objetiva do evento. Não o tendo previsto, cairá a atribuição dolosa do eventual crime; não the sendo previsivel, cairá a imputação sob a forma culposa excepcionalmente prevista. De um ou outro modo, conduz-se à solução absolutória.

\section{NOTAS}

1. É costumeira a afirmação de que no crime culposo a finalidade não é proibida. Ora, é possível que alguém, durante a prática de um crime doloso, quebre cuidados devidos na execução da correlata conduta e gere resultados puníveis culposamente. Então, para além da punição pelo crime doloso, haverá crime culposo em situação na qual o fim do agente era proibido.

2. Os critérios que orientam o dever de informação são: o cumprimento de um dever de informação, o grau de plausibilidade juridical da d'vuida, a necessidade de atuar nos limites desta dúvida. O cumprimento do dever de informação e atuar nos limites da dúvida sempre devem ser analisados de uma forma mais objetiva, na medida em que ou o sujeito cumpriu este dever ou não; ou se atuou nos limites, ou não. Já a plausibilidade juridical da dúvida é um critério graduavel e deve ser analisado de uma maneira mais elastica. 


\title{
COMPLIANCE AND NON-INTENTIONAL CRIMES: THE PROHIBITED RISK CATEGORY AS A TRYST
}

\begin{abstract}
Firstly, the article analyzes the origin and relevance of the compliance institute in the Brazilian territory and its dialogue with the Economic Criminal Law area, appreciating if the procedure is sufficient to maintain business activity in a permitted level risk. Is the non-observance of the intern compliance rules a reference to justify, in concrete situations, the creation of the prohibited risk? Preceding the answer in a deductive method, it will expose the theory of objective imputation, based on the predictability of exceeding the risk permission in companies in which the rules of a compliance manual are beacons for fixing behavioral patterns.
\end{abstract}

Keywords: Compliance; Prohibited Risk; Non-Intentional Crimes; Predictability; Economic Criminal Law.

\section{REFERENCIAS}

ALESSANDRI, Alberto. Diritto Penale e Attività Economiche. Bologna: Il Mulino, 2010.

AGLIETTA, Michel; REBÉRIOUX, Antoine. Corporate Governance Adrift: a critique of shareholder value. Cheltenham: Northampton: Edward Elgar, 2005.

ANTOLISEI, Francesco, Manuale di Diritto Penale: Parte Generale. 15. ed. Milalo: Giufrè, 2000.

BACIGALUPO, Enrique. Derecho Penal Parte General. 2. ed. Buenos Aires: Hammurabi, 1999.

BAJO FERNÁNDEZ, Miguel. "La delincuencia economica". In: Libro Homenaje al Prof. J. Antón Oneca. Salamanca: Ediciones Universidad de Salamanca, 1982.

BECK, Ulrich. La Sociedad del Riesgo Mundial. Barcelona: Paidós, 2008, p. 27.

BITENCOURT, Cezar Roberto; CONDE, Francisco Muñoz. Teoria Geral do Delito. São Paulo: Saraiva, 2000.

BITENCOURT, Cezar Roberto. Tratado de Direito Penal: Parte Geral. 13. ed. São Paulo: Saraiva, 2008.

BITENCOURT, Cezar Roberto; CONDE, Francisco Muñoz. Teoria Geral do Delito. São Paulo: Saraiva, 2000.

COSTA, Heitor Jr. Teoria dos Delitos Culposos. Rio de Janeiro: Iber Juris, 1988.

DEACON, Bob. Social Policy and Governance. London: Sage, 2007.

DEMETRIO CRESPO, Eduardo. Fundamento de la responsabilidad en comisión por omisión de los directivos de las empresas. In: SERRANO-PIEDECASAS, José Ramón; DEMETRIO CRESPO, Eduardo. Cuestiones Actuales de Derecho Penal Empresarial. Constitución y Leyes, S.A: Madrid, 2010.

DIAS, Jorge Figueiredo. Direito Penal: Parte Geral Tomo I - Questões Fundamentais à Doutrina do Crime. Coimbra: Coimbra, 2004. 
GUARAGNI, Fábio André. "Da tutela penal de interesses individuais aos supraindividuais: dialogando com Beccaria”. In: Ler Beccaria Hoje. (Coord. Paulo César Busato). Rio de Janeiro: Lumen Juris, 2009, pp. 55-65.

JAKOBS, Günther. Los Estudios de Derecho Penal. Madrid: Civitas, 1997.

JESCHECK, Hans-Heinrich; WEIGEND, Thomas. Tratado de Derecho Penal: Parte General. Granada: Comares, 2003.

LEITE, Alaor. Dúvida e erro sobre a proibição no direito penal. São Paulo: Atlas, 2013.

LUHMANN, Niklas. Sociologia do Risco. 3a . ed. Cidade do México: Universidad Iberoamericana, 2006.

MANZI, Alessi Vanessa. Compliance no Brasil: Consolidação e Perspectivas. São Paulo: Saint Paul, 2008.

MUARACH, Reinhart; GÖSSEL, Karl Heinz; ZIPF, Heinz. Derecho Penal: Parte General. vol. 2. Buenos Aires: Astrea, 1995.

OLIVARES, Gonzalo Quintero. Derecho Penal: Parte General. Madri: Marcial Pons, 1992.

PIERANGELI, José Henrique. Morte no trânsito: culpa consciente ou dolo eventual?, Justitia, v. 64, n. 197, p. 4763, jul./dez. 2007. Disponível em <http://bdjur.sti.jus.br/dspace/handle/2011/26014>. Acesso em: 12 out. 2014.

PUIG, Santiago Mir. Derecho Penal: Parte General. 6. ed. Barcelona: Repperton, 2002.

ROXIN, Claus. Derecho Penal: Parte General. Tomo I - Fundamentos. La estructura de la Teoría del Delito. 2. ed. Civitas, 1997.

SAAVEDRA, Giovani A. Reflexões iniciais sobre criminal compliance. Boletim IBCCRIM. São Paulo: IBCCRIM, ano 18, n. 218, p. 11-12, jan. 2011.

SÁNCHEZ, Bernando Feijoo. Problemas de imputación objetiva en el derecho penal económico y empresarial. In: SERRANO-PIEDECASAS, José Ramón; DEMETRIO CRESPO, Eduardo. Cuestiones Actuales de Derecho Penal Empresarial. Constitución y Leyes, S/A: Madrid, 2010.

SANCHEZ, Jesus Maria Silva. Criminalidad de Empresa Y Compliance: Prevención y reacciones corporativas. Barcelona: Atelier Libros, 2013.

TAVARES, Juarez. Curso de Direito Penal: Parte Geral. 4. ed. Rio de Janeiro: Impetus, 2004.

WEBER, Leonard. J. Business Ethics in Healthcare: Beyond Compliance. Bloomington and Indianapolis: Indiana University Press, 2001.

ZAFFARONI, Eugênio Raul apud Heitor Costa Junior. Teoria dos Delitos Culposos. Rio de Janeiro: Iber Juris, 1988.

ZAFFARONI, José Henrique; SLOKAR, Alejandro; ALAGIA, Alejandro. Derecho Penal: Parte Generale. 2. ed. Buenos Aires: Ediar, 2002. 
ZAFFARONI, José Henrique; PIERANGELI, Eugenio Raúl. Manual de Direito Penal Brasileiro: Parte Geral. 6. ed. Rev. e Atual. São Paulo: Revista dos Tribunais, 2006.

Trabalho enviado em 27 de agosto de 2015.

Aceito em 18 de outubro de 2015. 